\title{
RADIOJORNALISMO E OS VÁRIOS MODOS DA EXPERIÊNCIA SONORA: identidade, diversidade e pesquisa acadêmica nos novos contextos tecnológicos
}

RADIOJORNALISM AND THE VARIOUS MODES OF THE SOUND EXPERIENCE: identity, diversity, and academic research in the new technological contexts

\section{ENTREVISTA I INTERVIEW \\ Madalena OLIVEIRA I Universidade do Minho I Portugal}

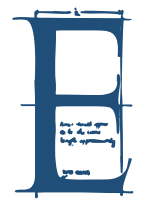

ntrevista concedida à Revista Latino-americana de Jornalismo Âncora por Madalena Oliveira, professora do Instituto de Ciências Sociais da Universidade do Minho e pesquisadora do Centro de Estudos de Comunicação e Sociedade. É doutora em Ciências da Comunicação pela Universidade do Minho (2007) e ensina habitualmente nas áreas de Semiótica, Linguagens e Jornalismo (especialmente Radiojornalismo). Seus interesses de investigação se situam no campo dos estudos de rádio e som, com particular enfoque na linguagem sonora e na produção de sentido a partir da experiência acústica. Coordena o projeto "Audire: guardar memórias sonoras", financiado pela Fundação para a Ciência e a Tecnologia (agência portuguesa de

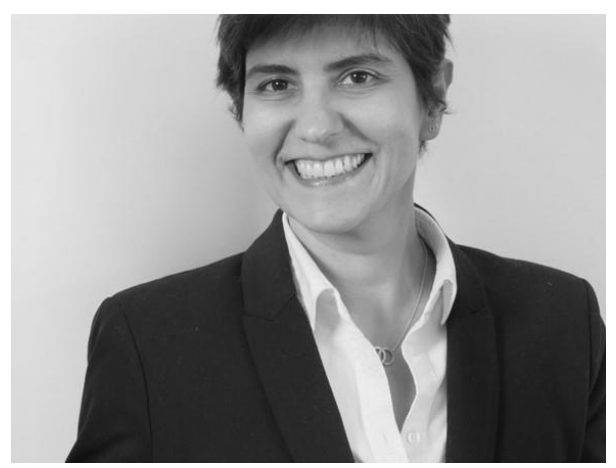
financiamento das atividades científicas). Fundou em 2013 o Grupo de Trabalho de Rádio e Meios Sonoros da Associação Portuguesa de Ciências da Comunicação (Sopcom) e foi chair da Radio Research Section da European Communication Research and Education Association (ECREA), entre 2014 e 2018. É vicepresidente do Instituto de Ciências Sociais da Universidade do Minho (desde 2019) e vice-presidente da Sopcom.

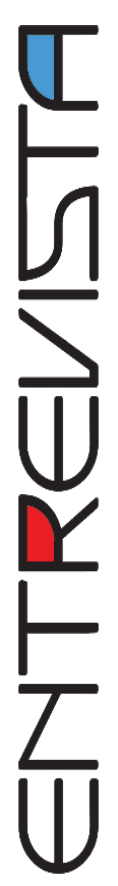

Palavras-chave | Radiojornalismo; Linguagem sonora; Experiência acústica; Estudos de rádio e som

Keywords I Radiojournalism; Sound language; Acoustic experience; Radio and sound studies 


\section{ANLORA}

ENTREVISTA - Madalena OLIVEIRA

\section{ÂNएORA}

Este dossiê reflete sobre as tendências e perspectivas do rádio e do radiojornalismo nos 100 anos de radiodifusão no Brasil. Na sua avaliação, existe um jornalismo de rádio? 0 que o difere dos outros modos do fazer jornalismo?

\section{Madalena OLIVEIRA}

Universidade do Minho | Portugal

Eu costumo dizer que, enquanto narrativa do presente, só há um jornalismo. Qualquer que seja o meio - a imprensa, o rádio, a televisão ou mesmo a internet -, o jornalismo tem sempre a mesma vocação, aquela que o escritor português Eça de Queirós definia como o "ir lá e voltar para contar aos outros". Por outro lado, os princípios por que se define a atividade jornalística também não são nem exclusivos de um tipo de veículo nem variáveis em função da plataforma em que se exprime. Nos jornais, no rádio, na TV ou na internet, o que distingue o jornalismo de qualquer outra atividade é a procura do novo, a perseguição da verdade, o interesse pelo singular e surpreendente que há nas histórias das pessoas. Não há, portanto, duas éticas

Madalena Oliveira Universidade do Minho

A principal razão por que o rádio
continua sendo um meio singular
é a sua orientação para o ouvido.
Ainda que hoje se fale da
transfiguração do rádio na
internet, onde ao som se pode
associar imagem, o rádio de que
falo continua sendo o rádio que
se ouve.

jornalísticas. $\mathrm{O}$ rigor, a independência, 0 respeito pela privacidade e pela diversidade cultural, o dever de prestar informação de qualidade... todos estes valores são universais para todos os jornalistas. O que há é várias estéticas jornalísticas. E aí, sim, podemos falar de um jornalismo de rádio, na medida em que se exercita numa linguagem distinta, porque exclusivamente sonora.

Se no passado poderíamos dizer que o jornalismo de rádio também se distinguia da imprensa (e em parte da televisão) por ser mais imediato, hoje, com a internet, essa já não é mais uma característica diferenciadora da produção radiofônica. É praticamente tão rápido colocar uma informação online como dizê-la ao microfone. A principal razão por que o rádio continua sendo um meio singular é a sua orientação para o ouvido. Ainda que hoje se fale da transfiguração do rádio na internet, onde ao som se pode associar imagem, o rádio de que falo continua sendo o rádio que se ouve. É nesse sentido que o jornalismo que se faz no rádio é diferente do jornalismo escrito ou audiovisual ou multimídia.

O jornalismo do rádio, na verdadeira acepção, é o jornalismo que dispensa a imagem e que concentra todo o poder narrativo na palavra e na experiência acústica. E isso não é apenas uma diferença de forma; é uma 
diferença que impacta na maneira como produzimos sentido, como construímos o nosso imaginário, como conhecemos a realidade. Numa cultura essencialmente visual como a nossa, é indiscutível que a imagem é central nos processos de comunicação. Ela é fascinante, é sedutora, é apelativa, pode ser comovente, é de leitura aparentemente fácil. Mas o som também pode produzir imagens. São as imagens que cada um de nós origina mentalmente a partir dos ambientes acústicos em que nos movimentamos.

O jornalismo de rádio é um produto da aprendizagem do poder

\section{0 radiojornalismo não é só \\ palavra falada. Tem sido cada \\ vez mais um ateliê de \\ artesanato sonoro.}

Madalena Oliveira

Universidade do Minho significativo do som. Nos primeiros anos da radiodifusão, liam-se os jornais aos ouvintes. Depois, foi-se percebendo que a escuta exige um delicado exercício da palavra simples, da frase curta e da coloquialidade. Porque fazemos outras coisas enquanto ouvimos, 0 jornalismo radiofônico - como toda a locução radiofônica - reclama ritmo, entoação e expressividade. No rádio, o jornalista não lê notícias; fala as notícias. Como disse recentemente o radialista português Fernando Alves, o rádio "é uma casa de onde as palavras se fazem ao vento". E para que o vento as leve é preciso que elas sejam ligeiras, o que não quer dizer simplistas; apenas que não tenham o peso que as impediria de dançar na memória.

Preferindo a palavra quotidiana e uma estrutura mais informal, o jornalismo de rádio presta-se também a ser mais generoso ou mais popular. Ele é - ou deve ser - tanto para a pessoa mais habilitada como para a menos instruída. E por ser também relativamente modesto do ponto de vista técnico, ele é ainda muito versátil, tem agilidade para a informação em direto e plasticidade para todos os gêneros jornalísticos, da notícia à reportagem ou da entrevista à crônica. $O$ jornalista vê e conta o que vê, mas acima de tudo o que o jornalista de rádio faz é ouvir o acontecimento. Ouve pessoas, ouve lugares, e os dá a ouvir ao público, que bem podemos designar neste meio mais do que em qualquer outro de audiência (que quer dizer, primeiramente, ato de ouvir).

\section{ÂNLORA}

\section{Quais são as principais tendências do radiojornalismo?}

\section{Madalena OLIVEIRA}

Universidade do Minhol Portugal

A principal tendência, do meu ponto de vista, é a da crescente estetização sonora de alguns gêneros, nomeadamente da reportagem. A 


\section{ANLORA \\ ENTREVISTA - Madalena OLIVEIRA}

aprendizagem da especificidade de uma linguagem para o rádio, de que eu falava antes, também tem criado uma maior sensibilidade para o valor expressivo do som. O radiojornalismo não é só palavra falada. Tem sido cada vez mais um ateliê de artesanato sonoro. E não é só porque dispomos hoje de ferramentas mais sofisticadas para a edição do som. Claro que isso é uma condição muito importante para a qualidade do trabalho que se realiza. É sobretudo porque há hoje uma maior consciência do potencial que tem a expressão sonora para produzir sentido.

Especialmente nos formatos mais longos, da grande reportagem, vamos encontrando cada vez mais trabalhos que têm um extraordinário valor em que se conjuga o relato da realidade com a experiência estética. Para além da narração dos fatos - que é a função primeira de todo o jornalismo -, o que o radiojornalismo também faz hoje, talvez mais do que no passado, é a assunção de que a informação sobre o que acontece também pode ser conhecida através das sensações. Nada disto se deve confundir com sensacionalismo, no entanto. Aliás, ao contrário da imprensa ou da televisão, o radiojornalismo raramente terá sido acusado de sensacionalismo.

\section{A produção de conteúdos jornalísticos em formato podcast é também uma tendência e uma oportunidade importante, numa estratégia de extensão do rádio tradicional para os novos contextos tecnológicos.}

Madalena Oliveira Universidade do Minho
A crítica fala de imprensa sensacionalista e de TV sensacionalista, mas não me lembro de se falar de rádio sensacionalista. Também haverá, mas o sensacionalismo, no sentido pejorativo do termo, não é um defeito muito comum do rádio. A crescente sensibilização de que falo relativamente ao discurso jornalístico radiofônico é a capacidade de fazer do mais pequeno detalhe, do som mais discreto (de uma porta que se abre ou fecha, dos passos de alguém que caminha...) uma fonte de emoções que são tão importantes para sentir a realidade que acontece como a descrição crua dos fatos.

Embora as condições de mercado sejam hoje pouco favoráveis ao desenvolvimento de trabalhos que estejam para além da urgência da atualidade imediata, também me parece que há uma tendência, ou pelo menos um anseio, para fazer mais um jornalismo sem pressa, o slow journalism. Ainda que o jornalismo de rádio esteja muito conotado com o imediato, a par da notícia do cotidiano - que é, de fato, sempre urgente -, o jornalista de rádio também vai procurando investir na exploração mais aprofundada de temas, que exigem tempo e que resultam em peças que podem ser autênticos registros históricos. É uma pena que não haja arquivos organizados desses trabalhos, que são importantes documentos de memória das gerações.

A produção de conteúdos jornalísticos em formato podcast é também uma tendência e uma oportunidade importante, numa estratégia de extensão do rádio tradicional para os novos contextos tecnológicos. Do ponto de vista da informação, o podcast é uma espécie de rádio por assinatura, ou de rádio 
on-demand. Embora esteja menos desenvolvido em Portugal do que no Brasil, este formato tem crescido e favorece a diversidade jornalística, a diversidade de formas de contar histórias, que é uma das vocações principais do jornalista. Vemos hoje uma tendência de vários meios para adotar o podcast como suporte de informação. Vários jornais começaram a produzir e publicar matéria jornalística neste formato, o que denota bem a relevância que o som também está adquirindo para outros meios que não tinham origem propriamente sonora.

No campo das tendências, também há que referir naturalmente uma tendência para uma certa hibridização. Com o imperativo de se adaptar à internet, o radiojornalismo vai-se reconfigurando num imperativo de combinar diferentes linguagens. Embora em rigor o multimídia seja outra coisa, o jornalismo de rádio que migra para o online cede à tentação de dar visibilidade à imagem e ao texto. É uma contradição, mas a internet, de fato, trai a natureza exclusivamente sonora do rádio. E pior, esconde o áudio. Sendo uma experiência de ecrã, o ciberespaço exige ser visto. Será por isso que os sites das emissoras de rádio - mesmo daquelas que têm uma natureza essencialmente informativa - têm uma aparência menos favorável ao produto sonoro do que se desejaria.

\section{ÂNLORA}

\section{Como fazer um jornalismo de rádio partindo do local até o transnacional?}

Madalena OLIVEIRA

Universidade do Minho | Portugal

\section{Com o estrangulamento \\ financeiro das empresas de radiodifusão, o desenvolvimento do jornalismo radiofônico local está seriamente comprometido.}

Madalena Oliveira Universidade do Minho
O rádio tem uma relevância extraordinária para as pequenas comunidades. No caso de Portugal, a história do rádio local - que nasceu do fenômeno do rádio pirata do fim da década de 1970 e de praticamente toda a década de 1980 - foi muito importante para uma certa descentralização do jornalismo dos grandes centros urbanos. A imprensa

regional já fazia isso, mas o rádio contribuiu decisivamente para amplificar a notícia do local. Infelizmente o setor da radiodifusão local hoje vive uma grave crise, com muitas emissoras sendo compradas por grandes cadeias sem licença nacional que procuram expandir o seu espectro de emissão através de processos de retransmissão. No contexto português, onde em 1989 foram legalizadas mais de 300 emissoras locais, o mercado revelou-se muito estreito para garantir a viabilidade econômica de todos esses projetos. Hoje assistimos 


\section{ANLORA \\ ENTREVISTA - Madalena OLIVEIRA}

a um fatal silenciamento do local.

Com o estrangulamento financeiro das empresas de radiodifusão, o desenvolvimento do jornalismo radiofônico local está seriamente comprometido. As emissoras portuguesas de âmbito não nacional têm muitas vezes redações muito estreitas, reduzidas em alguns casos a apenas um jornalista profissional. A escassez de investimento publicitário exigiria uma política de apoio a estas empresas que, infelizmente, ainda não existe. No quadro legal português, o rádio pode ser público ou comercial. No espectro hertziano, não há, por isso, espaço para a iniciativa comunitária, que poderia

\section{O radiojornalismo está, talvez, demasiado padronizado. Uma das grandes virtudes originais do rádio era o seu acolhimento e a sua abertura para a diversidade cultural.}

ser uma via alternativa para continuar a permitir a aliança entre o rádio e as populações mais deslocadas das principais cidades.

A internet é talvez o caminho de esperança para uma certa revitalização do local. Definindo-se por uma geografia sem fronteiras, 0 ciberespaço permite que o local se propague para o global. Os processos de globalização têm revelado mais uma tendência para apagar as idiossincrasias mais locais, mas precisamos de inverter esse processo. Acredito mesmo que é possível ver na internet uma forma de expandir de novo a identidade local. Hoje podemos ouvir rádios de todo o mundo através do streaming online. Ou seja, podemos propagar o local a uma escala transnacional. É essa a minha esperança.

Há uma rádio de informação portuguesa que, durante muitos anos, projetou o slogan "Vamos ao fim da rua, vamos ao fim do mundo". Precisamos que este seja um lema mais universal de todo o radiojornalismo. Precisamos que as emissoras nacionais tenham mais condições para investir na digressão pelo país. E precisamos de uma aposta em histórias novas que não estejam centradas apenas na agenda pública da política ou da economia nacional.

Como fazer para partir do local para o transnacional? Indo ao encontro das pessoas. Dando espaço àquilo que parece demasiado comum para a mídia nacional, ao que parece demasiado trivial ou demasiado secundário para estar nas primeiras páginas dos jornais nacionais ou nas portadas principais dos sites de informação nacional. A necessidade de informação estruturante para a cidadania - ao nível da política nacional e internacional, da cultura, da sociedade ou da economia - não é incompatível com o interesse pelas pequenas histórias. E são as pequenas histórias que, afinal, nos distinguem uns dos outros e nos tornam, por outro lado, tão atraídos uns pelos outros.

A programação de rádio está demasiado uniformizada. 0 radiojornalismo está, talvez, demasiado padronizado. Uma das grandes virtudes originais do rádio era o seu acolhimento e a sua abertura para a diversidade cultural. A minha convicção é que é nessa ideia de diversidade, tanto ao nível de conteúdos de entretenimento como ao nível da informação, que continuará a residir a força resiliente do rádio. A capacidade de inovação 
está ao alcance do radiojornalismo precisamente na aposta que se pode fazer no heterogêneo, no particular, no extraordinário. Temos tido uma curiosidade muito enérgica pelas imagens dos lugares distantes. 0 que o jornalismo radiofônico também pode levar para a esfera transnacional é a reverberação desses lugares, uma experiência que está longe de se ter esgotado na mundialização da mídia.

\section{ÂNLORA}

\section{A radiodifusão no Brasil está prestes a completar 100 anos. Como o outro lado do Atlântico percebe o rádio que fazemos aqui?}

\section{O Brasil é, por outro lado, um país de oralidade, de grande afetividade de palavra, de sonoridades musicais únicas. Não espanta que o rádio seja um meio com forte tradição e de franco sucesso.}

Madalena Oliveira Universidade do Minho

\section{Madalena OLIVEIRA}

Universidade do Minho | Portugal

Tanto quanto percebo a partir de Portugal, o rádio é um meio extremamente vivo no Brasil. Compreende-se bem porquê. $O$ rádio tem tanto de razão como de emoção. É exteriorização de afetos. Cria laços. É um meio quente, no conceito de Marshall McLuhan, porque prolonga um dos nossos sentidos - o da escuta - em "alta definição". Condiz bem com a identidade brasileira, desse ponto de vista, a identidade de um povo que também vive habitualmente em alta definição. O Brasil é, por outro lado, um país de oralidade, de grande afetividade de palavra, de sonoridades musicais únicas. Não espanta que 0 rádio seja um meio com forte tradição e de franco sucesso.

O desenvolvimento do setor no Brasil beneficiou também do fato de, ao contrário do que aconteceu na Europa, o aparecimento do rádio ter origem na iniciativa privada e não pela mão do Estado. Até à década de 1970, a indústria radiofônica em Portugal era relativamente estreita, centrada num triângulo que dominou a oferta nacional até à explosão das emissoras piratas, um triângulo formado pelo Rádio Clube Português, a Rádio Renascença (emissora católica) e a Emissora Nacional (emissora pública, que foi durante décadas o principal meio de comunicação pública do regime de Salazar). O rádio no Brasil foi mais expansivo desde o início.

O modelo de rádio brasileiro é, por outro lado, também mais diversificado. As emissoras podem ser públicas, estatais, comerciais, educativas ou comunitárias. Em Portugal, a legislação prevê apenas uma distinção entre público ou comercial, de âmbito territorial (internacional, nacional, regional ou local) e de tipo de programação (informativa ou temática). Não temos nenhuma tradição de rádio educativa. Algumas escolas 


\section{ANLORA \\ ENTREVISTA - Madalena OLIVEIRA}

de ensino pré-universitário têm ainda rádios escolares, uma experiência que foi muito forte nos anos 1990, muito por influência do fenômeno das piratas. As rádios universitárias, por seu lado, operam como rádios comerciais. Não há, por isso, um setor específico do rádio para fins educativos, muito embora já tenhamos alguns projetos de rádio dirigidos ao público infantil (como a Rádio Miúdos e a Rádio ZigZag). Também não temos emissoras comunitárias, que não têm enquadramento legal para a emissão hertziana. As iniciativas que conhecemos em Portugal nesse domínio são pouco numerosas e estão basicamente circunscritas ao online.

Daí que tenhamos uma ideia de que o rádio que se faz no Brasil é mais vibrante do que o nosso. Até pela extraordinária relevância que sabemos que este veículo continua a ter em regiões menos centrais, onde o rádio continua sendo um meio muito importante de contato entre as pessoas. O papel de algumas emissoras junto de grupos indígenas e de outras populações tradicionais é incrível. O "Programa de Índio" da Rádio USP de São Paulo, na segunda metade da década de 1980, é um exemplo extraordinário da função que o rádio pode ter na promoção de relações interculturais. 0 mesmo se pode dizer do rádio na favela, que tem uma função de socialização muito importante. Para além de dar voz à vida dessas comunidades, trata também temas específicos relacionados com os problemas desses aglomerados populacionais, como a violência, a pobreza, a discriminação e a droga. Por terem uma atenção muito particular aos modos de vida e às expressões culturais destes grupos habitacionais, estas emissoras também têm de algum modo uma função educativa. E são acima de tudo a prova de que o rádio é das pessoas, que o rádio não é apenas um veículo de transmissão, mas antes um meio que acolhe a participação. Essa, aliás, é uma marca muito forte do rádio, que desde muito cedo se abriu à participação dos ouvintes, a ouvir aqueles que o ouvem.

Competindo hoje com outros meios, eventualmente mais atraentes, como a televisão e a internet, o rádio no Brasil tem ainda muitas razões para acreditar no seu potencial. Num país que se conhece mundialmente por enormes desigualdades sociais, é ainda mais evidente o papel democrático que o rádio tem, por ser um meio de acesso praticamente universal.

\section{ÂNCORA \\ Que reflexões sobre o rádio seriam possíveis no atual cenário tecnológico?}

\section{Madalena OLIVEIRA}

Universidade do Minho | Portugal

O rádio sempre foi um meio pouco exigente do ponto de vista tecnológico. O seu desenvolvimento não foi, por isso, tão dependente do desenvolvimento de tecnologias. A imprensa e a televisão transformaram-se mais por força dos avanços tecnológicos do que o rádio. Claro que a digitalização do som facilitou o trabalho dos profissionais de rádio e dos sonoplastas. A criatividade ganhou muito com o aparecimento de ferramentas 
aptas para edição eletrônica do áudio. Porém, na sua traça original, o rádio sofreu poucas alterações. Já era espantoso o que se fazia, muito antes dos recursos digitais que agora existem, na época de ouro das radionovelas, com a produção de efeitos sonoros em regime totalmente analógico e de verdadeira rudimentaridade.

Atualmente há por certo um registro menos formal do que havia no passado, quando os locutores falavam em tom cerimonioso. Hoje o rádio é definitivamente mais descontraído. $\mathrm{E}$ isso também se deve à agilidade que os novos equipamentos permitiram do ponto de vista técnico. $O$ estúdio é hoje um espaço de informalidade, onde as grandes bobines de fita foram substituídas por painéis de botões. É isso que mostram os vídeos de programas de animação (muito característicos da programação matinal, por exemplo), onde se vê locutores que transgridem todos os protocolos clássicos de postura. Graças a esta simplificação técnica, o rádio agora também se produz facilmente e com toda a qualidade a partir de casa. A agilidade que a produção radiofônica ganhou bem pode ser uma nova oportunidade para os programas de autor e para o enriquecimento da programação. Dispensando o know-how especializado dos técnicos que antes operavam as emissões, a produção tornou-se muito acessível àqueles que tinham como função única dar voz à palavra.

O desenvolvimento dos sistemas digitais de operação radiofônica também permitiu a automação das emissões, o que tem contribuído, do ponto de vista dos profissionais, para um certo desencantamento da comunicação de rádio. Com os estúdios a poder funcionar só com máquinas pré-programadas, é o fascínio e a ansiedade do direto o que se perde.

$\mathrm{O}$ atual cenário tecnológico é, portanto, ambíguo para o rádio. Se, por um lado, se tornaram mais amigáveis e mais rápidos os meios de produção, se se criaram condições para uma realização mais autónoma, se se diversificaram as oportunidades de transmissão e se apareceram novos canais de interação com o público, especialmente com a transição das ondas hertzianas para as ondas de navegação na internet, por outro, há uma certa magia que se arrisca a enfraquecer. É também de perda de magia que se fala quando se passa a conhecer o rosto daqueles que falam ao microfone. A visualização do rádio que os sites passaram a viabilizar compromete o encanto que havia no locutor desconhecido, que apenas se imaginava.

Em termos de recepção, é claro que o rádio beneficia muito do atual cenário tecnológico. Se bem que também aqui há riscos. Embora possamos escutar rádio enquanto trabalhamos, a internet tem um efeito muito dispersivo. $\mathrm{E}$ havendo todas as condições para que o rádio continuasse a ser o som de fundo de todas as nossas atividades diárias, a concorrência dos serviços de streaming de música é uma ameaça de que o rádio só poderá salvar-se se fizer um investimento em conteúdos alternativos, se não estiver refém da transmissão musical e se, para isso, contrariar a tendência para essa

João Pessoa - Brasil | ANO 7 VOL.7 N.1 | JAN./JUL. 2020 | p.474-492

Revista Latino-americana de Jornalismo | ISSN 2359-375X

Programa de Pós-Graduação em Jornalismo - UFPB

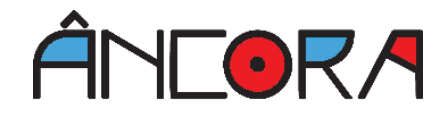




\section{ANLORA}

ENTREVISTA - Madalena OLIVEIRA

automação das emissões de que falava antes... se, no fundo, o rádio apostar num regresso pleno das pessoas e das suas histórias.

\section{ÂNए尺RA}

Uma das conquistas da existência do rádio no Brasil, nestes últimos 100 anos, foi o processo de institucionalização de um campo de saber científico. É possível identificar, principalmente nos últimos anos, o aumento de pesquisas em rádio, pesquisadores brasileiros consolidando trajetórias de estudo e pesquisa, temas diversos, abrangentes e variados sendo objeto de teses, dissertações, trabalhos de conclusão de curso e iniciação científica, maior número de artigos com temática radiofônica aprovados em Congressos do campo da Comunicação e do Jornalismo, calendário anual com Congressos, Simpósios e outros eventos científicos na área de rádio, além de muitas revistas científicas, fora as específicas já existentes, trazerem temas relacionados ao rádio em suas edições. Como uma pesquisadora muito próxima e atenta analisa este processo de institucionalização do rádio brasileiro?

\section{Madalena OLIVEIRA}

Universidade do Minho | Portugal

O desenvolvimento dos estudos de rádio foi muito tardio. $\mathrm{O}$ fato de $\mathrm{O}$ campo científico da Comunicação se ter constituído só em meados do século XX explica, em parte, a progressão lenta que tiveram as pesquisas sobre este setor. É que, quando a Comunicação se funda como área de conhecimento, o meio que estava realmente a deslumbrar as audiências já era a televisão. Daí que, apesar de terem existido alguns estudos sobre a influência da mídia nos públicos focados no rádio nas décadas de 1930 e 1940, muito depressa o interesse dos pesquisadores se concentrou mais nos ecrãs do que na comunicação sonora. Por outro lado, o rádio é um meio cego, o som tem uma

\begin{abstract}
0 desenvolvimento dos estudos de rádio foi muito tardio. $\mathbf{O}$ fato de o campo científico da Comunicação se ter constituído só em meados do século XX explica, em parte, a progressão lenta que tiveram as pesquisas sobre este setor.
\end{abstract}

Madalena Oliveira Universidade do Minho natureza aparentemente intangível, e é difícil estudar o que não se vê. Agravado pela limitação de acesso a material empírico, o estudo do rádio foi-se tornando secundário. É comum dizermos que o rádio é o parente pobre, um meio marginal ou marginalizado, na pesquisa de mídia. $E$ é verdade. Também porque o setor do rádio tem menos impacto econômico do que outros meios. 0 próprio investimento publicitário no rádio é inferior ao investimento arrecadado pela televisão (e, pelo menos no passado, ao investimento direcionado para a imprensa).

Durante muito tempo, a produção científica sobre o rádio foi residual. E muitos trabalhos, de âmbito mais instrumental, como os manuais de 
produção, subordinavam o rádio à televisão, quase sugerindo que a televisão era um meio que, tendo desenvolvido a técnica radiofônica, superava as suas limitações. Hoje, felizmente já não é bem assim. Os estudos de rádio e de som têm conhecido um desenvolvimento extraordinário em todo o mundo. O Brasil começou mais cedo que Portugal. O grupo de Rádio e Mídia Sonora da Intercom tem quase 30 anos! Em Portugal, pelo contrário, a nossa história é muito mais recente. Fundámos em 2013 o grupo de Rádio e Meios Sonoros da Sopcom - Associação Portuguesa de Ciências da Comunicação, copiando o nome dos nossos companheiros brasileiros. Somos ainda um grupo muito pequeno, de pouco mais de duas dezenas de pesquisadores. No entanto, é assinalável o entusiasmo e o dinamismo deste grupo. Em alguns congressos também registramos mais propostas de comunicação do que os estudos de televisão, por exemplo.

O número de dissertações de Mestrado e de teses de Doutorado está a crescer. A primeira tese de Doutorado sobre rádio em Portugal é de 1991, mas a falta de tradição nesta área não favoreceu muito a formação de novos académicos. Durante alguns anos trabalhámos de modo atomizado, sem formar coletivos. A pouca sensibilidade dos avaliadores de linhas de financiamento para o rádio, um meio considerado, por preconceito, ultrapassado, também não contribuiu para um desenvolvimento mais rápido. Sendo um país muito maior, com faculdades de Comunicação de grande dimensão, o Brasil tem tido um papel excepcional na projeção de estudos em língua portuguesa sobre a indústria, a produção, a linguagem e o impacto do rádio nas sociedades. Essa institucionalização de um campo de saber científico específico é fundamental para o futuro do rádio, não só por permitir conhecer de forma mais sistemática o papel que as emissoras têm no entretenimento como na informação, mas também por contribuir para a valorização da comunicação sonora como uma forma de expressão e de socialização tão singular.

Costumo dizer que os pesquisadores de rádio formam uma comunidade muito fundada em relações de solidariedade que estão em sintonia com 0 espírito do próprio rádio. Ao contrário de outras áreas científicas, onde eventualmente é mais evidente uma dinâmica competitiva, entre os pesquisadores de rádio, a nível nacional e internacional, há um vínculo afetivo que torna ainda mais profícua a experiência científica. Talvez porque muitos tiveram experiências profissionais prévias no rádio e partilham aquilo que chamamos habitualmente de "paixão do rádio". O certo é que também no domínio da pesquisa o rádio tem uma alma resiliente.

\section{ÂNLORA}

Qual a importância e papel do rádio neste momento de pandemia, com pessoas do mundo inteiro infectadas pelo novo coronavírus, em um cenário de mortes em elevado número, isolamento social,

João Pessoa - Brasil | ANO 7 VOL.7 N.1 | JAN./JUL. 2020 | p.474-492

Revista Latino-americana de Jornalismo | ISSN 2359-375X

Programa de Pós-Graduação em Jornalismo - UFPB

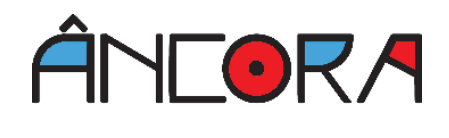




\section{ANEORA \\ ENTREVISTA - Madalena OLIVEIRA}

comércios fechados, cidades paradas e fortes indicativos de grande descuido com a saúde pública em nível mundial?

\section{Madalena OLIVEIRA}

Universidade do Minho | Portugal

Ao contrário de outros momentos críticos, de catástrofes naturais, por exemplo, creio que o papel do rádio neste momento de pandemia tem sido menos saliente. $\mathrm{O}$ que talvez tenha uma explicação relativamente fácil. 0 confinamento e o dever de isolamento fecharam as pessoas em casa. E em casa a experiência midiática é mais centrada nos ecrãs, no computador, na internet e na televisão. 0 rádio é um meio que consumimos em movimento. 0 chamado drive-time é muito importante para as audiências de rádio, porque 0 tempo de viagem é um tempo muito propício à sintonia do rádio. Ora, com menos deslocações, o rádio terá sido facilmente preterido.

O maior aumento de consumo de mídia ter-se-á registrado para a televisão. Também os jornais terão sido muito mais consultados do que em momentos normais. Não em papel, até porque as vendas tiveram constrangimentos severos, com postos de distribuição em muitos casos encerrados; mas no online, a procura de informação aumentou extraordinariamente. Vários meios deram conta de uma subida substancial do número de visitas aos seus sites. Os primeiros estudos conhecidos sobre audiências neste primeiro semestre de 2020 também referem algum crescimento da audiência de rádio nos primeiros meses da pandemia. Sei que no Brasil isso se verificou. Dados do Kantar IBOPE Media revelam que a escuta de rádio continua crescendo desde o início da crise sanitária. É um bom sinal e corrobora outros estudos que também indicam que o grau de confiança que as pessoas têm na mídia é maior no rádio do que em outros meios.

Imagino que para as populações rurais ou com acesso limitado à internet, o rádio tem uma importância tremenda. Se já em situações normais é um veículo de informação decisivo para quem tem dificuldade de acesso à imprensa ou mesmo constrangimentos de acesso à diversidade de canais de TV, num momento como o que vivemos é ainda mais importante a transmissão regular de atualizações, inclusive, sobre as recomendações das autoridades sanitárias. O rádio pode ser uma voz de alerta e ter um papel crucial para levar os esclarecimentos de especialistas ao conhecimento das audiências. Acredito que em algumas localidades o rádio é o meio mais eficaz de veicular orientações para comportamentos preventivos e de segurança. Por outro lado, posso imaginar que, no espírito da sua missão interativa, algumas emissoras terão aberto canais de "atendimento" de interpelações dos ouvintes, que estarão ajudando a esclarecer dúvidas, a acalmar populações mais assustadas e a desmontar notícias falsas. Essa interação direta com as pessoas é um exclusivo do rádio, sem equivalente nos jornais e na televisão.

Para além da informação, a função cultural do rádio pode igualmente acentuar-se ainda mais. Com o cancelamento de espetáculos, o encerramento dos espaços culturais e de lazer e com a proibição de festas e romarias, a programação radiofônica tem uma oportunidade acrescida de se tornar numa 
via alternativa aos eventos artístico-culturais. Esse papel foi bastante assumido pela TV e pela internet, que transmitiram shows musicais, por exemplo em direto do Facebook. Também os sistemas de cinema on-demand (da TV a cabo, por exemplo) e o Netflix terão beneficiado bastante deste período em que todo o tipo de consumo de distração se fez a partir de casa. Mas acredito que em alguns contextos essa função também foi procurada no rádio.

\section{ÂN}

Num exercício de prospecção sobre o futuro do rádio e do jornalismo, - que seria importante destacar deste momento que estamos vivendo que pode ser indicativo para possíveis novos modos de fazer e escutar o rádio e fazer jornalismo?

\section{Madalena OLIVEIRA}

Universidade do Minho | Portugal

Olhar para diante, fazer prospecção sobre o futuro é sempre um exercício ousado. Não tenho segurança suficiente para prever o que vai acontecer. $\mathrm{O}$ que me atrevo a fazer é mais pensar em desafios. $\mathrm{O}$ maior de todos julgo que é, tanto para o rádio como para o jornalismo, o de reverter a ideia que começou a instalar-se de que serão dispensáveis.

Com a circulação global de informação, o acesso aparentemente universal a informação por outras vias que não a mídia convencional, tem começado a parecer que já não precisamos nem do jornalismo nem dos jornalistas. Grande equívoco, por, pelo menos, duas razões. Primeiro, porque o que o jornalismo faz é mais do que agregar e transmitir informação. Os jornalistas procuram, selecionam, valorizam, enfim, crivam, separam o essencial do acessório, facilitam a compreensão dos fatos. Depois, porque a quantidade de informação disponível não é necessariamente sinónimo de qualidade. Os processos de desinformação a que hoje assistimos são, em certo sentido, um efeito do enfraquecimento das condições de atuação do jornalismo e da fragilização dos jornalistas do ponto de vista profissional. O desafio dos séculos XIX e XX era o de dar acesso. O desafio do nosso tempo é mais o de validar aquilo a que se tem acesso. $E$ isso é algo que podemos, ou precisamos mesmo, de continuar a confiar aos jornalistas.

Também com o rádio o desafio é um pouco o de provar que continua a ser relevante. Apesar da diversificação dos meios e das linguagens, e sobretudo do multimídia, seria um logro tomar o rádio como um meio desnecessário. Pela sua portabilidade e pela sua linguagem específica, o rádio não é substituível por nenhum outro meio, nem mesmo aqueles que superam as suas aparentes - e só aparentes - limitações. Por outro lado, como já referi antes, o rádio alcança populações que não estão no radar de outros veículos.

Penso que perspetivar o futuro do jornalismo passará ainda por

João Pessoa - Brasil | ANO 7 VOL.7 N.1 | JAN./JUL. 2020 | p.474-492

Revista Latino-americana de Jornalismo | ISSN 2359-375X

Programa de Pós-Graduação em Jornalismo - UFPB

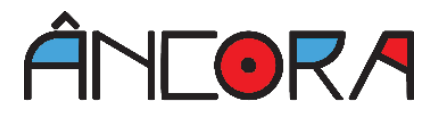




\section{ANLORA \\ ENTREVISTA - Madalena OLIVEIRA}

repensar seriamente os modelos de financiamento desta atividade. Não poderemos continuar a olhar para a informação jornalística como um produto que pode continuar sendo ou tem de ser gratuito. Ou através do apoio às audiências ou através do apoio às empresas jornalísticas, será necessário reconsiderar o valor da atividade jornalística, sob pena de retirarmos ao jornalismo qualquer hipótese de viabilidade econômica para exercer o papel que dele esperamos de contribuir para a capacitação dos públicos para uma cidadania ativa e comprometida. Creio que não podemos continuar não pagando por um trabalho que tem de ser visto como essencial.

No caso do rádio em particular, parece-me que olhar para diante significará pensar em como tirar melhor partido da internet, que não deveria ser apenas uma espécie de nova antena. $\mathrm{O}$ ciberespaço e os novos formatos, como o podcast, deveriam também ser um desafio de inovação levado mais a sério. Aquilo que o rádio oferece hoje na internet ou é apenas a repetição dos conteúdos emitidos em antena ou produtos de natureza multimídia, em tudo equivalentes aos dos sites de outras mídias, sobretudo os jornais. Inovar significa apostar em novos gêneros, por exemplo, na ficção. As radionovelas foram produtos muito bem-sucedidos. Talvez também uma maior especialização temática como estratégia para fixar novos públicos e para preencher lacunas que, eventualmente, estão a descoberto na mídia generalista. O rádio, de fato, não pode continuar a olhar para o público como uma massa homogênea. $O$ tempo da chamada comunicação de massas já lá vai. Hoje é mais o tempo de uma comunicação de tribos, de comunidades, não necessariamente geográficas, mas comunidades de interesses. Isso já existe um pouco no rádio, por exemplo, ao nível da música, com rádios especializadas em música clássica ou jazz. Mas o conceito de rádio especializado pode ser aprofundado. Ainda há espaço para inventar coisas. Ou para insistir em coisas já inventadas, mas pouco difundidas (as rádios de hospital, as rádios autoestrada...).

\section{ÂNட९RA}

De que maneira é possível pensar os vínculos entre as culturas de ouvir e os modos de produzir rádio ontem e hoje?

Madalena OLIVEIRA

Universidade do Minho | Portugal

É possível que a diferença entre o "ontem" e o "hoje" esteja na maneira como passámos a relacionar-nos com a imagem. É impossível falar de cultura de ouvir sem falar de cultura de imagem. Com as tecnologias digitais, o visual passou a ser o modelo predominante de comunicação, mas sempre foi, de algum modo, um sentido prioritário. Até na nossa linguagem cotidiana damos sinais dessa prioridade que damos ao ver. Dizemos "deixa eu te mostrar essa música...", quando o verbo mostrar quer dizer "expor à vista, fazer ver"; falamos de "pontos de vista", sempre de vista, nunca de escuta; falamos "ver $T_{V}$ ", que também é, normalmente, escutar a TV; a expressão "à vista 
desarmada", que quer dizer "a olho nu", não tem, que eu me lembre, qualquer equivalente para o ouvido... Estamos definitivamente muito mais orientados socialmente para ver do que para escutar. A visão será, inclusive, o nosso sentido preponderante. Se, por absurdo, tivéssemos, de repente, que escolher entre ficar cegos ou ficar surdos, imagino que a maioria de nós (se não mesmo todos nós) diria ficar surdo. Na verdade, sendo natural essa escolha, ela também tem a ver com o fato de não termos nenhuma ideia do que será a experiência de não ouvir. Sabemos o que será não ver, porque fechamos ou vendamos os olhos e percebemos a sensação de escuridão. Associamos a cegueira a essa escuridão. Não sabemos, no entanto, o que será o silêncio absoluto, porque nunca conseguimos deixar de escutar. Mesmo quando "tapamos" os ouvidos, nunca ficamos no grau zero do som. O ouvido já funciona dentro do ventre materno e é um sentido que não se desliga, não tem pálpebras. Por causa disso, julgo eu, temos menos consciência da importância que o ouvido tem para a nossa orientação no espaço, por exemplo.

Nos anos de ouro do rádio, antes do aparecimento da televisão, as famílias sentavam-se em redor da telefonia para escutar um determinado programa. Um pouco como se fez anos depois para ver a telenovela, por exemplo. Hoje ninguém se senta para escutar. Pelo contrário, escutamos sobretudo em movimento, enquanto nos deslocamos ou enquanto trabalhamos. Não creio, no entanto, que a causa disso seja o modo como se passou a produzir rádio. Até diria o contrário. É porque o ritmo das nossas vidas mudou tanto, num sentido de aceleração, que o rádio também se acelerou. A programação de rádio tem um certo frenesim. Já está longe de ser um espaço de cerimónias.

Que proximidades anoto eu entre a nossa cultura auditiva e a maneira como ouvimos rádio? Pois, em primeiro lugar essa questão do movimento. Depois, o fato de fazermos outras coisas enquanto escutamos. A escuta é um sentido de simultaneidades. E o rádio também é assim, não exige exclusividade.

Há um outro aspeto que também julgo importante salientar. As nossas sociedades são sociedades manifestamente ruidosas. Há um autor britânico, David Hendy, que diz que a modernidade é ruidosa, atribuindo à Revolução Industrial o início de uma época que começou a conviver com o barulho em permanência, sobretudo por causa do barulho próprio das máquinas (máquinas de produção, motores de veículos, etc.). Eu acho que também isso contribuiu para o modo como se faz rádio hoje. O ruído ajuda o ouvido a ser distraído, porque o requisita para outros sons que acontecem à volta para além das frequências que intencionalmente sintonizamos. Com essa percepção, os profissionais de rádio foram descobrindo que a mensagem radiofônica precisa de ter estímulos ativadores da atenção, como os jingles, por exemplo, ou os tapetes sonoros dos programas, ou os sons ambiente de um trabalho de

João Pessoa - Brasil | ANO 7 VOL.7 N.1 | JAN./JUL. 2020 | p.474-492

Revista Latino-americana de Jornalismo | ISSN 2359-375X

Programa de Pós-Graduação em Jornalismo - UFPB

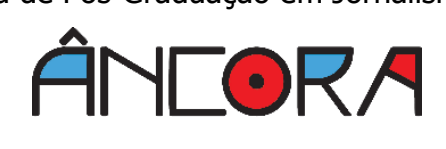




\section{ÂNटORA \\ ENTREVISTA - Madalena OLIVEIRA}

reportagem. A mensagem radiofônica nunca pode ser monocórdica, nem na voz nem nos outros elementos sonoros.

\section{ÂNए९RA}

Diversas vezes já ouvimos falar na "morte do rádio"; no entanto, o meio sempre se reconfigura, se (re)afirma, se "radiomorfoseia". Na sua avaliação, qual a principal força motora do rádio e de que maneira ele pode se manter firme?

\section{Madalena OLIVEIRA}

Universidade do Minho | Portugal

Não sou capaz de distinguir apenas uma força motora principal. Sendo verdade que essa capacidade para se metamorfosear é um dos principais trunfos que o rádio tem posto em evidência na resposta aos vaticínios de morte, o rádio tem várias forças. Uma delas é a simplicidade. Relativa simplicidade técnica. No limite, hoje podem produzir-se conteúdos quase usando exclusivamente o smartphone. Aí as aplicações de gravação e edição são limitadas, mas já permitem fazer coisas, ter a edição sonora ao alcance de um dispositivo que está mesmo ali à mão. As tecnologias de recepção também são muito simples, tão simples que as temos não apenas em aparelhos portáteis que funcionam com baterias / pilhas pouco exigentes, como as temos incorporadas no carro. Simplicidade de linguagem. Como mencionei já várias vezes durante esta entrevista, a linguagem do rádio é simples e acessível. Não exige especiais aprendizagens para quem escuta.

A instantaneidade já não é mais uma característica exclusiva do rádio. A TV também conquistou alguma instantaneidade, apenas comprometida pela preocupação adicional com a imagem, que o rádio dispensa. A internet beneficia igualmente de instantaneidade. A diferença principal é que a internet

\section{0 rádio tem boa reputação junto das audiências, sendo mesmo um dos meios mais confiáveis em termos de informação.}

Madalena Oliveira Universidade do Minho ainda não chega a todas as pessoas e a todos os lugares. Isso continua sendo um privilégio, um trunfo exclusivo do rádio. Aos olhos de alguns, provavelmente 0 rádio poderia existir apenas para cumprir essa função de chegar aonde outros não chegam, uma espécie de meio dos mais pobres ou desfavorecidos. Não é, no entanto, crível que o rádio "morra" no mundo desenvolvido para ter apenas uma função missionária em territórios desvalidos.

Outras forças: uma presença discreta que saiu mais ou menos imune das críticas que se dirigem à mídia em geral (não se fala em sensacionalismo; não se sugere a existência de uma relação entre o rádio e a obesidade infantil ou a violência, como se chegou a sugerir relativamente à TV...); um elevado potencial de confiança dos ouvintes. O rádio tem boa reputação junto das audiências, sendo mesmo um dos meios mais confiáveis em termos de informação; um sentido de abertura à participação (que, na minha opinião, 
até poderia ser ainda mais explorado); a capacidade de se misturar com outros meios, sem lhes roubar protagonismo...

\section{Não concebo bem a ideia de um rádio multimídia, do mesmo modo que não concebo bem a ideia de um jornal multimídia. Há a imprensa, o rádio, a TV e o multimídia. São categorias distintas.}

Madalena Oliveira Universidade do Minho

Eu não sou uma especial entusiasta de uma hibridização do rádio no sentido da mistura de linguagens. Penso mesmo que essa virada para o multimídia não é bem o rádio a reinventar-se... é mais o rádio a entregar a sua alma. A radiomorfose é a transformação do rádio sem sair do rádio, isto é, sem sair da sua natureza, que é, como disse no início desta entrevista, uma natureza exclusivamente sonora. Que o rádio se adapte a outras plataformas, que transmita a partir da internet e não apenas do ar, que procure recriar formatos, inovar nos gêneros, que acompanhe os ritmos e estilos de vida, que explore a participação direta do ouvinte na própria produção... tudo isso me parece muito bem, altamente desejável e totalmente ao alcance da plasticidade que o rádio tem tido ao longo de diferentes gerações. Que o rádio incorpore a imagem, por exemplo, é já do domínio de uma coisa diferente. O multimídia não é um upgrade das mídias convencionais. O multimídia é uma realidade nova. Não concebo bem a ideia de um rádio multimídia, do mesmo modo que não concebo bem a ideia de um jornal multimídia. Há a imprensa, o rádio, a TV e o multimídia. São categorias distintas. Portanto, a mim parece-me que, se for por aí, por uma ideia de hibridização e transfiguração multimídia, o rádio perderá essa tal força por que tem sido um meio resiliente e dará lugar a um meio onde já pouco se reconhecerá desse mundo encantado da caixinha de som.

\section{ÂNLORA}

Qual a importância das pesquisas em rádio e radiojornalismo, bem como da formação adequada dos profissionais do rádio para que o meio cumpra sua função social?

\section{Madalena OLIVEIRA}

Universidade do Minho | Portugal

Há entre os pesquisadores de rádio e radiojornalismo a ideia de que começamos tarde, somos poucos e nos levam pouco a sério. Somos encarados como pesquisadores nostálgicos, porque mesmo quando falamos do futuro do rádio, estamos, dizem, agarrados à saudade de um meio cujo tempo já passou. Esses são os preconceitos com que convivemos e penso que não nos deixamos abater por isso. No campo da formação, porém, creio que temos de pensar de

João Pessoa - Brasil | ANO 7 VOL.7 N.1 | JAN./JUL. 2020 | p.474-492

Revista Latino-americana de Jornalismo | ISSN 2359-375X

Programa de Pós-Graduação em Jornalismo - UFPB 


\section{ANICORA}

ENTREVISTA - Madalena OLIVEIRA

outro modo, porque esses tais preconceitos e a secundarização do meio rádio nos estudos da mídia têm impacto muito significativo na maneira como ensinamos nas nossas universidades.

Os cursos de Comunicação e Jornalismo têm planos de estudos (ementas de matérias) com inúmeras disciplinas ligadas à imagem. Semiótica Visual, Teoria e Análise da Imagem, Cultura Visual, Design e Visualidades, Fotografia, Vídeo... nada disto tem equivalente no som. Na generalidade dos cursos de graduação não temos matérias específicas de Semiótica Sonora, nem Teoria e Análise do Som ou Cultura Sonora... Mesmo quando falamos de História da Comunicação, a história do som e do rádio é geralmente um capítulo menor. Seria muito importante que repensássemos o que estamos a ensinar. Não creio que estejamos a preparar uma geração para uma
No caso da Universidade do
Minho [...] a disciplina de radiojornalismo passou a chamar-se Jornalismo e Som, para dar espaço a formatos de jornalismo sonoro não exclusivamente para o meio rádio; e criámos também uma disciplina de Sonoplastia".

Madalena Oliveira Universidade do Minho maior sensibilidade ao som. Nem para produzir conteúdos sonoros nem para saber ouvir, querer ouvir. Falo genericamente, porque claro que há exceções. O que vejo, no entanto, é um fascínio pelo multimídia, pelo transmídia, pela convergência que pode comprometer muito as nossas competências nas linguagens originais.

No caso de Portugal, fazemos um ensino do rádio muito fechado exclusivamente no radiojornalismo. Tudo o que ensinamos de locução, por exemplo, está normalmente condicionado à prática jornalística. Não preparamos para a produção de outro tipo de conteúdos. E dentro do radiojornalismo, temo que ainda estejamos muito presos aos gêneros convencionais, a notícia, a entrevista, a reportagem, o noticiário (o boletim da hora cheia...). Precisaríamos que os cursos tivessem mais tempo para estas matérias, para podermos sair da esfera do ensino básico do radiojornalismo. No caso da Universidade do Minho, já demos alguns passos nos últimos anos: a disciplina de radiojornalismo passou a chamar-se Jornalismo e Som, para dar espaço a formatos de jornalismo sonoro não exclusivamente para o meio rádio; e criámos também uma disciplina de Sonoplastia.

Para além da formação específica no âmbito dos cursos de Comunicação e Jornalismo, também seria importante que tivéssemos mais espaço para cultivar uma certa literacia sonora. Não só nas universidades. O próprio ensino médio e fundamental poderia usar mais recursos sonoros para fins pedagógicos. Sinto que se utiliza muito o vídeo, por exemplo, mas que se convida pouco a ouvir durante os processos de ensino/aprendizagem. Embora esta preocupação esteja para além da formação dos profissionais de rádio, penso que, se queremos falar de uma cultura do som, precisamos de levar mais o áudio para dentro da sala de aula.

Eu gostaria que a formação que fazemos nas universidades fosse mais 
diversificada em matéria de criação sonora. A inovação no meio também depende disso. Felizmente vamos fazendo algumas atividades extracurriculares que compensam as lacunas dos currículos. E ao nível da pesquisa também estamos procurando servir mais os propósitos de formação, promovendo ações híbridas, que combinam a pesquisa fundamental com pesquisa aplicada, intervenção e ensino.

Sem querer ter uma posição muito normativa, diria que é por este triângulo (pesquisa, intervenção e ensino) que passa a responsabilidade da academia para com o meio rádio. Preparar os profissionais para recriar o meio e exercer um jornalismo de qualidade, a par da produção de estudos que possam inclusive justificar políticas de apoio são tarefas de que a universidade não se poderá demitir sob pena de ela própria contribuir para um certo apagamento do rádio da paisagem midiática. 